\title{
Interconnected Dimensions of University Autonomy in Europe
}

\author{
Kata Orosz
}

\section{Introduction}

University autonomy is a concept that is difficult to pin down, as its meaning tends to vary across national contexts and over time (Iwinska and Matei n.d.; Pruvot and Estermann 2017; Karran et al. 2017; Nokkala and Bacevic 2014; Piironen 2013; Tapper and Salter 1995; Wright and Ørberg 2008; Yokoyama 2007). Some (e.g., Pruvot and Estermann 2017) define university autonomy as the power of the institution to manage its internal affairs without undue external influence. Karran et al. (2017) consider institutional autonomy to be a dimension of academic freedom, which they describe as the power of faculty and students to teach, research, and contribute to the governance of the university. Others (e.g., Iwinska and Matei n.d.) define university autonomy as a concept that characterizes both the relationship between the university and external actors, as well as the activities that are carried out by university faculty and students. Some studies differentiate between "substantive" and "procedural" autonomy; the first refers to the ability of universities to set goals for themselves, while the latter refers to the ability of universities to decide how they will pursue these goals (Baschung et al. 2011).

While it may not be possible to provide a single definition of university autonomy, there is a consensus in published literature that university autonomy is a multi-dimensional concept (e.g., Aghion et al. 2010; Estermann and Nokkala 2009; Iwinska and Matei n.d.; Oliveira Martins et al. 2009; Volkwein 1986). The numbers and names of dimension vary greatly across published studies. For example, Volkwein (1986) distinguishes only two dimensions of campus autonomy: academic and financial. The European University Association (2017) defines four dimensions of university autonomy: organizational, financial, staffing, and

K. Orosz $(\bowtie)$

Central European University, Nádor utca 9, Budapest 1051, Hungary

e-mail: oroszk@ceu.edu

(C) The Author(s) 2018

A. Curaj et al. (eds.), European Higher Education Area: The Impact of Past and Future Policies, https://doi.org/10.1007/978-3-319-77407-7_38 
academic. Iwinska and Matei (n.d.) describe a total of eight dimensions, based on their review of prior comparative studies of university autonomy: (1) internal governance and organization; (2) curriculum, program design and teaching methods; (3) research and publications; (4) quality assurance and academic standards; (5) student-related issues; (6) staff-related issues (both academic and non-academic university staff); (7) finance and administration; and (8) internationalization-related topics.

When discussing the multiple dimensions of university autonomy, authors have hinted at the existence of interconnections between different dimensions. Karran et al. (2017) created a five-dimensional measure of academic freedom in the $28 \mathrm{EU}$ countries. In calculating the overall score of academic freedom for each country, the authors did not assign different weights to the five dimensions, but rather, they assumed that all five dimensions - institutional autonomy, freedom to teach and research, participation in self-governance, presence of academic tenure, and adherence to international agreements on academic freedom-were equally important for measuring academic freedom. Karran et al. (2017) acknowledge that the "relative importance" of the dimensions may vary but they argue that "individual elements are less important than the fact that they mesh together" (p. 212) and bring up the example of the presence of tenure, which they see as a necessary but not sufficient condition of university self-governance.

The methodological annex of the 2017 EUA scorecard on university autonomy in Europe mentions the "various and intricate connections between the different autonomy areas" (Pruvot and Estermann 2017, p. 64) and stipulates a connection between financial and staffing autonomy, but the authors do not explain what connects these two dimensions conceptually and whether such a connection, in fact, exists in the sample of countries that participated in the EUA survey on autonomy. This paper sets out to address this existing gap in knowledge and to empirically investigate whether different dimensions of university autonomy in Europe are connected. Understanding whether and how different dimensions of university autonomy are connected and how they may influence each other is of paramount interest to policymakers and university leaders, especially in the context of growing public concerns about the declining financial autonomy of European universities (Bothwell 2017; Kováts 2015; Pruvot and Estermann 2017).

\section{Data and Analytical Approach}

This paper uses statistical analyses to empirically test whether different dimensions of university autonomy in European higher education are connected. Specifically, the paper addresses the following research question: Are there relationships between the four dimensions of university autonomy, as defined and operationalized by the European University Association?

The data used in the study comes from the 2017 EUA scorecard (Pruvot and Estermann 2017). The EUA methodology operationalizes university autonomy as 
the extent to which public universities are free from "constraint which stems from a legal provision [and] constraints originating from decisions by the ministry or other types of public bodies" (Pruvot and Estermann 2017, p. 11). Autonomy scores in each dimension are based on information from questionnaires and interviews conducted with members of the rectors' conferences of participating higher education systems, who are asked to assess the legal and ministerial constraints that affect university activities.

The EUA methodology for calculating autonomy scores can be described as criterion-referenced. Karran et al. (2017), who used a methodology like the one developed by EUA in their own study of academic freedom in Europe, describe the benefit of this criterion-referenced approach by emphasizing that it allows researchers to derive "individual scores [for each country], which would show how closely a nation comes to meeting all its commitments" and to track changes in country performance over time (p. 210). The weighted autonomy scores for each country and each dimension are publicly available in the 2017 EUA scorecard as well as on EUA's University Autonomy in Europe website (http://www.universityautonomy.eu/).

The EUA autonomy scores are calculated based on a total of 32 indicators, which are grouped into four dimensions. The scores are calculated using a double system of weighting a country's score within each of the four dimensions. On the one hand, the EUA methodology weights country scores on individual autonomy indicators through a system of "deductions". Each country for each of the 32 indicators is, by default, scored at $100 \%$ of the scale on which the indicator is measured. (The number of scalar units varies across indicators.) The $100 \%$ is interpreted as the total absence of external influence on the institutional activity that is measured by the indicator. Countries get percentage point deductions for each restriction that is placed on the given activity; a value of $0 \%$ means that the activity is fully determined externally, without input from the university. Deductions are not uniform: the magnitude of percentage point deduction that corresponds to each type of restriction on the activity was determined by EUA experts. For example, the indicator "Capacity to decide on the overall number of students"- which is one of the indicators that make up the academic autonomy dimension-can take five possible values. One value which stipulates that the overall number of students is the independent decision of universities corresponds to 0-point deduction from the maximum score of 5 that a country can receive on this measure. Two extreme values - one which stipulates that student numbers are "negotiated between universities and an external authority", and another one which stipulates that student numbers are the "exclusive decision of an external authority" (p. 62) - correspond to 5 points deduction each. The indicator can also take two other values, with restrictions that were perceived to be less restrictive than the two extreme values, which correspond to a deduction of 2 points (or $40 \%$ of the default score) each. This system of deductions weights country performance on each indicator based on the perceived severity of the imposition on institutional autonomy that each restriction poses. 
In addition, EUA also applies a system of weights to calculate the autonomy scores of each higher education system for each of the four autonomy dimensions. Autonomy scores of a country within a given dimension are indices of the indicators that make up that dimension. Each of the indicators that belong to the same dimension is weighted by the "importance value" of the indicator (Pruvot and Estermann 2017, p. 63), which is the relative importance of the given indicator, as rated by EUA members who participated in the organization's annual conference in 2010. For example, within the dimension of financial autonomy, any restrictions placed on public universities' ability to charge tuition fees for non-EU students accounts for $21 \%$ of a country's overall score in the financial autonomy dimension, compared to restrictions placed on the public universities' ability to borrow money, which accounts for $9 \%$ of the financial autonomy score. EUA's weighting system of deductions and importance values means that legislative or ministerial restrictions placed on certain university activities affect a country's autonomy scores more than others.

The EUA defines and operationalises four dimensions of university autonomy in Europe: academic, financial, organizational, and staffing autonomy (Pruvot and Estermann 2017). To test whether there are any relationships between each of these four dimensions of university autonomy, I used information on the weighted autonomy scores of 24 European countries that participated in the 2015-2016 EUA survey. Although the 2017 EUA scorecard provides information on a total of 29 higher education systems, I excluded information on higher education systems of sub-national regions from my analysis to keep my analytic sample more homogeneous from a legislative standpoint. The following 24 European countries were included in my analysis: Austria, Croatia, Denmark, Estonia, Finland, France, Hungary, Iceland, Ireland, Italy, Latvia, Lithuania, Luxembourg, the Netherlands, Norway, Poland, Portugal, Serbia, Slovakia, Slovenia, Spain, Sweden, Switzerland, United Kingdom.

I conducted three analytical steps to explore the relationships, if any, between each of the four dimensions of university autonomy, as defined and operationalized by the EUA. First, I plotted autonomy scores and calculated bivariate correlation coefficients of the four dimensions of university autonomy to determine whether there is any indication of a linear relationship between any of the two pairs. In the second step, I conducted ordinary least squares (OLS) regression analyses of all four dimensions combined to test whether the combination of any three dimensions explains the variation in the fourth dimension. Finally, I conducted Fisher's exact tests to determine whether any of the detected linear relationships between autonomy dimensions are statistically significant. I used STATA 13.0 software for all of the statistical analyses. 


\section{Findings}

Descriptive information about the four variables in the analyses - that is, the weighted autonomy scores of the 24 countries that make up the analytic sample-is displayed in Table 1. The statistics show that university autonomy in Europe varies across the four dimensions: on average, European public universities enjoy greater autonomy in terms of staffing decisions (mean $=70.125$ ) and organizational structures $($ mean $=67.458)$, than in terms of their finances $($ mean $=62.458)$ and control over academic matters (mean $=62.125)$.

Descriptive statistics also show that, while at least some countries are free of any external influence in terms of organizational structures and staffing decisions (a maximum autonomy score of 100), all of the 24 European countries in the analytic sample have some kind of external limitation in terms of financial and academic matters. Also noteworthy is the fact that none of the countries in the analytic sample exerts full external control over the activities of public universities; the lowest minimum value for university autonomy in any dimension is 21 (on a scale of 0 to 100).

Figure 1 displays each of the four autonomy dimensions plotted against the other three dimensions, in a pairwise manner. The plots do not suggest a clear pattern of linear relationships between the autonomy dimensions, with the exception of staffing and academic autonomy: the plots for these two dimensions display the distinct pattern associated with a positive linear relationship. The calculation of pairwise correlation coefficients paints a picture of a positive linear relationship between each of the four autonomy dimensions, albeit the correlations are small-to-moderate in size. The bivariate correlation coefficients of the pairs, in ascending order: financial and organizational autonomy $(r=0.11)$, financial and academic autonomy $(r=0.24)$, organizational and staffing autonomy $(r=0.29)$, organizational and academic autonomy $(r=0.32)$, financial and staffing autonomy $(\mathrm{r}=0.40)$, and staffing and academic autonomy $(\mathrm{r}=0.50)$.

Results from the OLS regression analyses are reported in Table 2. The results suggest that the average level of staffing autonomy in the 24 European countries of the analytic sample is explained reasonably well with variation in the autonomy levels in the other three dimensions. In Model 1, variation in organizational, financial, and academic autonomy levels explains one-fourth of the variation in the

Table 1 Descriptive statistics of the four dimensions of university autonomy

\begin{tabular}{l|l|l|l|l}
\hline Variable name & Mean & $\begin{array}{l}\text { Standard } \\
\text { deviation }\end{array}$ & $\begin{array}{l}\text { Minimum } \\
\text { value }\end{array}$ & $\begin{array}{l}\text { Maximum } \\
\text { value }\end{array}$ \\
\hline $\begin{array}{l}\text { Organizational } \\
\text { autonomy }\end{array}$ & 67.458 & 17.141 & 34 & 100 \\
\hline Financial autonomy & 62.458 & 16.626 & 21 & 91 \\
\hline Staffing autonomy & 70.125 & 20.970 & 37 & 100 \\
\hline Academic autonomy & 62.125 & 18.092 & 37 & 98 \\
\hline
\end{tabular}




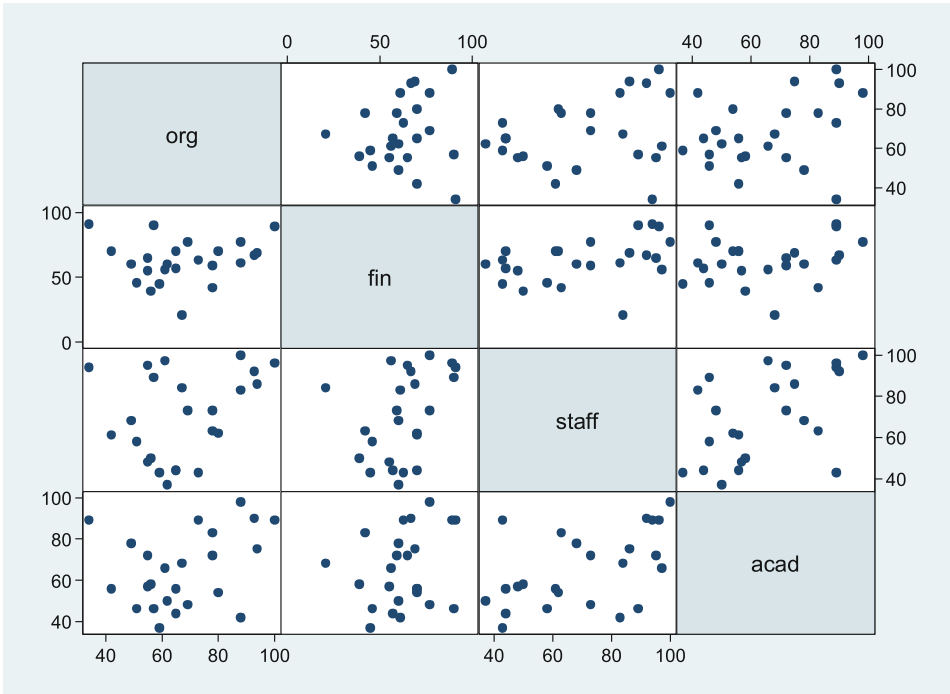

Fig. 1 Matrix of pairwise scatterplots of autonomy scores

level of staffing autonomy (adjusted R-squared $=0.25$ ); the result is statistically significant at the 0.05 alpha level $(\mathrm{F}=0.0308)$. The beta coefficient for academic autonomy is positive and approaches statistical significance in Model 1. In the "inverse" model-Model 2, in which staffing autonomy is used in combination with financial and organizational autonomy to explain variation in academic autonomy - the coefficient for staffing autonomy is also positive and approaching statistical significance, although the overall model is not statistically significant.

The finding that staffing autonomy and academic autonomy are positively linked is further confirmed by regression analyses in which the two variables were used to predict each other. Results from these analyses show that staffing autonomy explains more than one-fifth of the variation in academic autonomy (adjusted $\mathrm{R}$-squared $=0.22$ ) and vice versa. The results are statistically significant at the 0.05 alpha level $(\mathrm{F}=0.0120)$.

There is some indication that financial autonomy may be positively associated with staffing autonomy, but the association is modest - the bivariate correlation is 0.40 , the adjusted R-squared of the bivariate regression coefficient is 0.12 - and not statistically significant at the conventional alpha level of 0.05 . The beta coefficients for financial autonomy and organizational autonomy are negative in the models in which they are used to predict each other (Models 3 and 4), although the results are not statistically significant. Like the results from bivariate correlations, these findings also suggest that there is no evidence of a linear relationship between the financial and organizational dimensions of university autonomy.

In the final analytical step, instead of treating autonomy scores as interval variables, I grouped countries in the analytic sample into categories of high- and 
Table 2 Regression output from analyses of the four dimensions of autonomy

\begin{tabular}{|c|c|c|}
\hline \multicolumn{3}{|c|}{ Model 1: Predicting staffing autonomy } \\
\hline $\mathrm{F}$ & & $0.0308^{\mathrm{a}}$ \\
\hline Adjusted R-squared & & 0.2549 \\
\hline \multirow[t]{3}{*}{ Coefficients $(p>t)$} & Organizational a. & $0.168(0.477)$ \\
\hline & Financial a. & $0.364(0.135)$ \\
\hline & Academic a. & $0.451(0.059)$ \\
\hline \multicolumn{3}{|c|}{ Model 2: Predicting academic autonomy } \\
\hline $\mathrm{F}$ & & 0.0723 \\
\hline Adjusted R-squared & & 0.1825 \\
\hline \multirow[t]{3}{*}{ Coefficients $(p>t)$} & Organizational a. & $0.201(0.346)$ \\
\hline & Financial a. & $0.056(0.806)$ \\
\hline & Staffing a. & $0.369(0.059)$ \\
\hline \multicolumn{3}{|c|}{ Model 3: Predicting financial autonomy } \\
\hline $\mathrm{F}$ & & 0.3068 \\
\hline Adjusted R-squared & & 0.0358 \\
\hline \multirow[t]{3}{*}{ Coefficients $(p>t)$} & Organizational a. & $-0.019(0.927)$ \\
\hline & Academic a. & $0.055(0.806)$ \\
\hline & Staffing a. & $0.296(0.135)$ \\
\hline \multicolumn{3}{|c|}{ Model 4: Predicting organizational autonomy } \\
\hline $\mathrm{F}$ & & 0.4239 \\
\hline Adjusted R-squared & & -0.0032 \\
\hline \multirow[t]{3}{*}{ Coefficients $(p>t)$} & Financial a. & $-0.0217(0.927)$ \\
\hline & Academic a. & $0.221(0.346)$ \\
\hline & Staffing a. & $0.151(0.477)$ \\
\hline
\end{tabular}

${ }^{a}$ Results that are statistically significant at the $95 \%$ confidence level.

low-autonomy for each dimension. The 2017 EUA scorecard clusters higher education systems by autonomy scores within each dimension. Higher education systems that received a score in the band of $100-81 \%$ are rated by the EUA as having high autonomy in the given dimension; systems in the $80-61 \%$ band are rated as having medium-high, systems in the $60-41 \%$ band as medium-low, and systems with $40 \%$ and below as having low level of autonomy in the given dimension (Pruvot and Estermann 2017). The distribution of autonomy scores in each dimension of the 2017 EUA scorecard is clustered around the center: there are only a few countries that are rated as belonging to low autonomy clusters and only a few more that are in the high autonomy clusters. I grouped the countries in the two extreme clusters with countries in the corresponding central clusters for the purposes of my analyses. Therefore, in the discussion of my findings that follows, "countries with high autonomy" refers to countries that were ranked in the high and middle-high clusters of the 2017 EUA scorecard, while "countries with low autonomy" refers to countries that were ranked in the low and middle-low clusters of the 2017 EUA scorecard.

I conducted six sets of Fisher's exact test to test the statistical significance of the relationships between different dimensions of university autonomy. Fisher's exact 
Table 3 Results from the analysis of contingency tables of the four autonomy dimensions

\begin{tabular}{l|l}
\hline Autonomy dimensions & Fisher's exact probability \\
\hline Organizational and financial & 0.675 \\
\hline Organizational and staffing & 0.412 \\
\hline Organizational and academic & 0.400 \\
\hline Financial and staffing & 0.082 \\
\hline Financial and academic & 1.000 \\
\hline Staffing and academic & $0.027^{\mathrm{a}}$
\end{tabular}

${ }^{\mathrm{a}}$ Results that are statistically significant at the $95 \%$ confidence level.

test was developed to be used in the analysis of contingency tables; its use is especially recommended when sample sizes are small (Agresti 1992). The contingency Tables I compiled compared the number of countries with low and high levels of autonomy in one dimension with the number of countries with low and high levels of autonomy in another dimension. Table 3 displays the results from the Fisher's exact test of the six contingency tables. Results from the Fisher's tests indicate that the positive relationship between the dimensions of staffing autonomy and academic autonomy that was identified in the previous analytic steps is statistically significant at the 0.05 alpha level $(p=0.027)$.

\section{Discussion and Conclusions}

The key finding from this study is that the dimensions of financial, organizational, and academic autonomy are not systematically linked to each other in a linear manner in the European context. In the 2017 EUA scorecard, we find examples of countries in which high levels of financial autonomy go hand-in-hand with high levels of organizational autonomy (e.g., the United Kingdom or Estonia); countries in which both organizational and financial autonomy levels are low (e.g., Serbia, Spain); countries in which public universities have low organizational autonomy with high autonomy over finances (e.g., Luxembourg, Slovakia), as well as countries in which institutions have high organizational autonomy with low autonomy over finances (e.g., Norway, Poland).

The lack of evidence of prominent linear relationships between the autonomy levels of European universities in the organizational, financial, and academic dimensions is consistent with empirical evidence on higher education reform worldwide. In studying the introduction of autonomy to Kazakhstan's higher education system, Hartley et al. (2016) found that universities were granted more autonomy in some areas (e.g., curriculum design) and less autonomy in others (e.g., hiring of faculty, keeping surplus). In the case of Hungary, Kováts (2015) found that the passing of the National Higher Education Act of 2011 resulted in the shrinking of university autonomy in the organizational and financial areas, but did not affect the staffing autonomy of universities. These and other studies (e.g., Varghese and Martin 1986.) document how legal frameworks and policies that 
regulate public higher education institutions change over time and how legislators and policymakers frequently emphasize increased institutional responsibilities (through granting universities more autonomy) in some areas, while simultaneously maintaining or increasing control in other areas of institutional activity.

The single exception to the overall pattern of no association is the finding that staffing and academic autonomy are significantly positively associated with each other in European higher education. In other words, countries with high levels of staffing autonomy tend to have high levels of academic autonomy, while countries with low levels of staffing autonomy tend to have low levels of academic autonomy. A possible explanation of the moderately, but significantly positive association between staffing autonomy and academic autonomy may be explained by the operationalization of these dimensions by the EUA: the two dimensions are made up by indicators that measure conceptually related items.

Economists of higher education (e.g., Toutkoushian and Paulsen 2016) use the concept of production function to conceptualize the activities of higher education institutions. In this framework, the inputs of the university's production function are the students; the production process involves university employees (faculty and staff), physical facilities and equipment, and the curriculum; and the outputs are the students, "now more learned and developed" (Toutkoushian and Paulsen 2016, p. 301). In the 2017 EUA scorecard, academic autonomy is comprised of seven indicators: (1) capacity to decide on overall student numbers, (2) ability to select students, (3) ability to introduce programs, (4) ability to terminate programs, (5) ability to choose the language of instruction, (6) capacity to select quality assurance mechanisms and providers, and (7) ability to design the content of degree programs. The EUA dimension of staffing autonomy is comprised of four indicators: the ability of universities to decide on (1) the recruitment procedures, (2) the salary, (3) the dismissal, and (4) the promotion of faculty and staff (Pruvot and Estermann 2017).

Mapping the EUA indicators on the conceptual framework of higher education production functions shows that all four indicators of the staffing autonomy dimension, and indicators 3 through 7 of the academic autonomy dimension can be conceptualized as elements of the "production process", whereas the first two indicators of the academic autonomy dimension (which pertain to the number and "quality" of students) can be conceptualized as the "inputs". A possible explanation of the positive relationship between the EUA measures of staffing and academic autonomy could be that they are statically related because both capture information about the same concept - the higher education "production process." Presumably, when policymakers decide that universities should have more (or less) autonomy in how they "produce" students, they design policies that affect the entire "production process", from faculty to curriculum and program design, rather than singling out only certain aspects of the "production process."

The hypothesis that the EUA staffing and academic autonomy dimensions are statistically related due to the conceptual similarity of the four staffing autonomy indicators and most of the academic autonomy indicators can be tested by re-grouping all "production process" indicators as a single dimension and treating 
the two "input" indicators as a separate dimension. If it is indeed the conceptual similarity that explains the statistical relationship, one would expect that there will be no relationship between the two new dimensions since they would consist of conceptually distinct items.

In conclusion, there is little evidence from the analysis of EUA autonomy scores to suggest that distinct dimensions of university autonomy are systematically linked in European higher education. The statistically significant positive link between academic and staffing autonomy seems to be an artefact of the measurement methodology of the EUA scorecard. However, the finding of no association between different dimensions of university autonomy should not be taken to mean that different configurations of "substantive" autonomy do not have implications for the "procedural" autonomy of European universities (Baschung et al. 2011). For example, universities may have procedural autonomy in how they establish new degree programs, but their substantive autonomy of how many degree programs they can establish will be dependent on whether decisions on the funding for new programs are made internally or externally. A fruitful avenue for future research is to explore the links between substantive and procedural autonomy in European higher education systems.

\section{References}

Aghion, P., Dewatripont, M., Hoxby, C., Mas-Colell, A., \& Sapir, A. (2010). The governance and performance of universities: Evidence from Europe and the US. Economic Policy, 25(61), 7 59.

Agresti, A. (1992). A survey of exact inference for contingency tables. Statistical Science, 7(1), 131-153.

Baschung, L., Goastellec, G., \& Leresche, J. (2011). Universities' autonomy in times of changing higher education governance: A study of the Swiss academic labour market. Tertiary Education and Management, 17(1), 51-64.

Bothwell, E. (2017). University autonomy in Europe 'hit by austerity'. Times Higher Education. Retrieved from http://www.timeshighereducation.com/news/university-autonomy-in-europehit-by-austerity.

Estermann, T., \& Nokkala, T. (2009). University Autonomy in Europe: An Exploratory Study. Brussels: European University Association.

Hartley, M., Gopaul, B., Sagintayeva, A., \& Apergenova, R. (2016). Learning autonomy: Higher education reform in Kazakhstan. Higher Education, 72(3), 277-289.

Iwinska, J., \& Matei, L. (n.d.). University autonomy: A practical handbook. Budapest: Central European University.

Karran, T., Beiter, K., \& Appiagyei-Atua, K. (2017). Measuring academic freedom in Europe: A criterion referenced approach. Policy Reviews in Higher Education, 1(2), 209-239.

Kováts, G. (2015). Recent developments in the autonomy and governance of higher education institutions in Hungary: The introduction of the chancellor system. Central European Higher Education Cooperation Conference of Budapest (pp. 26-39).

Nokkala, T., \& Bacevic, J. (2014). University autonomy, agenda setting and the construction of agency: The case of the European university association in the European higher education area. European Educational Research Journal, 13(6), 699-714. 
Oliveira Martins, J., Boarini, R., Strauss, H., \& de la Maisonneuve, C. (2009). The policy determinants of investment in tertiary education. OECD Economics Department Working Papers No. 576. Paris: OECD.

Piironen, O. (2013). The transnational idea of university autonomy and the reform of the Finnish Universities Act. Higher Education Policy, 26(1), 127-146.

Pruvot, E. B., \& Estermann, T. (2017). University autonomy in Europe III: The scorecard 2017. Brussels: European University Association.

Tapper, E. R., \& Salter, B. G. (1995). The changing idea of university autonomy. Studies in Higher Education, 20(1), 59-71.

Toutkoushian, R. K., \& Paulsen, M. B. (2016). Competition and production in higher education. In R. K. Toutkoushian \& M. B. Paulsen (Eds.), Economics of higher education (pp. 275-322). Dordrecht: Springer.

Varghese, N. V., \& Martin, M. (1986). Governance reforms in higher education: A study of institutional autonomy in Asian countries. Paris: UNESCO.

Volkwein, J. F. (1986). Campus autonomy and its relationship to measures of university quality. Journal of Higher Education, 57(5), 510-528.

Wright, S., \& Ørberg, J. W. (2008). Autonomy and control: Danish university reform in the context of modern governance. Learning and Teaching, 1(1), 27-57.

Yokoyama, K. (2007). Changing definitions of university autonomy: The cases of England and Japan. Higher Education in Europe, 32(4), 399-409.

Open Access This chapter is licensed under the terms of the Creative Commons Attribution 4.0 International License (http://creativecommons.org/licenses/by/4.0/), which permits use, sharing, adaptation, distribution and reproduction in any medium or format, as long as you give appropriate credit to the original author(s) and the source, provide a link to the Creative Commons license and indicate if changes were made.

The images or other third party material in this chapter are included in the chapter's Creative Commons license, unless indicated otherwise in a credit line to the material. If material is not included in the chapter's Creative Commons license and your intended use is not permitted by statutory regulation or exceeds the permitted use, you will need to obtain permission directly from the copyright holder. 